\title{
A brief review of synthesis and catalytic applications of graphene-coated oxides
}

\author{
Wen Luo ${ }^{a *}$, Spyridon Zafeiratos ${ }^{b}$
}

\begin{abstract}
The potential applications of graphene-based materials in catalysis have been intensively studied due to the unique $2 \mathrm{D}$ structure of graphene and its superior physicochemical properties. Recently, graphene-coated oxide composites have been fabricated and tested as catalysts or catalytic supports, demonstrating a significant improvement on the catalytic performance. This article briefly reviews the recent progress in the design and fabrication of graphene-coated oxides including wet transfer, chemical vapor deposition and self-assembly methods. The applications of these materials in catalysis as well as the role of graphene in the modification of oxide properties and the enhancement of catalytic activity are also discussed.
\end{abstract}

\section{Introduction}

Graphene is a single layer of carbon atoms tightly packed in a hexagonal lattice. Since its discovery in 2004 via "Scotch tape" method ${ }^{[1]}$, graphene has attracted enormous attention due to its unique properties, such as high charge carrier mobility $\left(\sim 2 \times 10^{5}\right.$ $\left.\mathrm{cm}^{2} \mathrm{~V}^{-1} \mathrm{~S}^{-1}\right)^{[2,3]}$, high thermal conductivity $\left(5000 \mathrm{Wm}^{-1} \mathrm{~K}^{-1}\right)^{[4]}$, extremely high specific surface area $\left(\sim 2600 \mathrm{~m}^{2} \mathrm{~g}^{-1}\right.$ for a single layer) ${ }^{[5]}$ and increased transparency ${ }^{[6]}$. All these superior properties make graphene an attractive catalytic material and in the last few years, the number of publications exploiting graphene as photo- or electro-catalyst has been exponentially increased. Notably, heteroatom-doped graphene (nitrogen [7], sulfur ${ }^{[8]}$, boron ${ }^{[9]}$ etc.) have shown much better electrocatalytic activity and long-term operation stability for oxygen reduction reaction. When used as catalysts' support, the high specific surface area of graphene can improve the metal dispersion and therefore increase the catalyst activity and stability ${ }^{[10]}$. However, the intrinsic characteristics of graphene are unfavorable for some specific catalytic applications. For example, graphene is a zero bandgap material and therefore cannot be used directly as a photocatalyst. Furthermore, the free-standing single layer graphene is often corrugated and wrinkled, or even recombines to form few-layer graphene, therefore loses many of its unique properties mentioned above.

Oxides are long-established materials in catalytic applications and they possess some certain advantages which cannot be

[a] Dr. Wen LUO, Institute of Chemical Sciences and Engineering (ISIC), École Polytechnique Fédérale de Lausanne (EPFL), 1950 Sion, Switzerland. E-mail:wen.luo@epfl.ch

[b] Dr. Spyridon ZAFEIRATOS, Institut de Chimie et Procédés pour I'Energie, l'Environnement et la Santé (ICPEES), ECPM, UMR 7515 CNRS-Université de Strasbourg, 25, rue Becquerel, 67087 Strasbourg Cedex 02, France. easily attained by graphene. These advantages comprise low preparation cost, variable band gap, good mechanical properties and facility to be prepared in different shapes and forms. However, oxides have also some major shortcomings when they are used in catalysis. For example, $\mathrm{SiO}_{2}$ and $\mathrm{Al}_{2} \mathrm{O}_{3}$ have been widely applied as catalytic supports in Fischer-Tropsch reaction since they can sufficiently disperse the active metals (Co, Fe etc.). However the formation of unreducible mixed oxides between metal catalyst and support during the preparation and the reaction process has been blamed for irreversible deactivation of the catalyst ${ }^{[11,12]}$. Similarly, while $\mathrm{ZnO}$ and $\mathrm{CeO}_{2}$ are considered to have potentially promising applications in ethanol steam reforming reaction, the oxidation of active metal sites (such as Co) by the support decreases the catalytic activity ${ }^{[13,14]}$. In the case of photocatalytic reactions, $\mathrm{TiO}_{2}$ is the most widely studied material ${ }^{[15,16]}$, but still engineering of its band-gap to absorb more in the visible electromagnetic radiation region remains a difficult problem.

In recent years, hybrid materials consisting of graphene-coated metal oxides have gained increasing attention with the hope to find a nanocomposite material which overcomes the shortcomings of both graphene and oxides and promotes the catalytic performance. For instance, graphene has the potential to be an ideal buffer layer to protect metal catalysts from deactivation induced by the interfacial reaction with oxide supports, since it is one atomic layer thick, but at the same time rigid and impermeable to support constituents accountable for oxidation ${ }^{[17]}$. In addition, coating semiconductor oxides (such as $\mathrm{TiO}_{2}$ and $\mathrm{ZnO}$ ) with graphene can effectively decrease their bandgap leading to higher absorption yields in the visible light region $[18,19]$. Close contact of graphene with coated semiconductor oxides can also enhance the charge transfer efficiency, thus increases the catalytic activity.

Studies of graphene either as a catalytic support or as a metalfree catalyst, have been summarized in some comprehensive reviews ${ }^{[20-25]}$. However, an overview emphasizing on the synthesis and catalytic applications of graphene-coated metal oxides is lacking, and given that the research on these hybrid materials is progressing fast, such a report is greatly needed. This review briefly describes the recent progress in the design and fabrication of graphene-coated metal oxides and discusses the specific advantages of these materials in photo- and heterogeneous catalysis (Fig. 1). Some major challenges and future opportunities for further development are also discussed. 


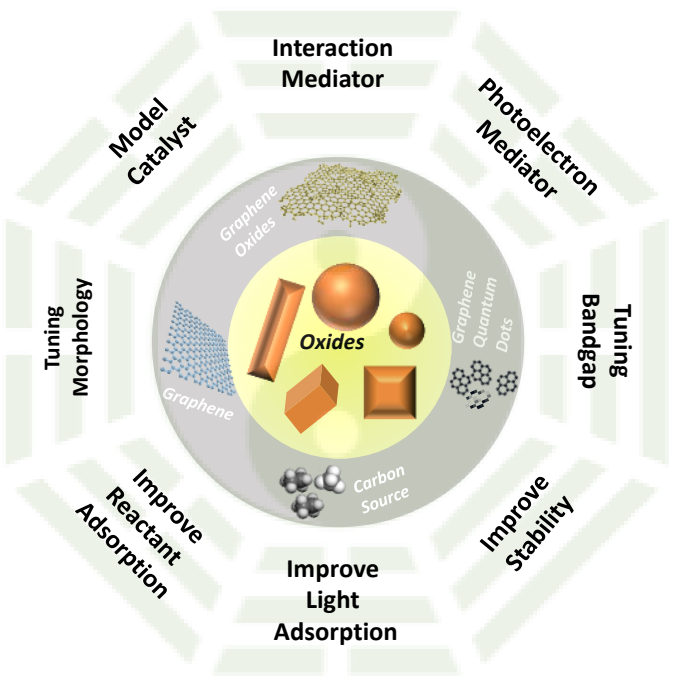

Figure 1. Schematic illustration of the multi-functionality of graphene coated oxides in heterogeneous catalysis.

\section{Preparation strategies for graphene-coated metal oxide supports}

\subsection{Metal oxide supports with planar morphology}

As a single carbon layer, graphene is a perfect candidate to produce planar, highly-controlled model catalysts, for detailed studies of the interaction between carbon and metals, as well as carbon with gas molecules. The most facile method to prepare graphene-coated oxide model samples is by transferring preformed graphene layers onto planar oxide substrates using the so called wet transfer method. A schematic diagram of the transfer process is shown in Fig. $2^{[26]}$. Initially, large-area graphene layers are produced on metal substrates, through chemical vapor deposition (CVD) method. Next, the graphene layer is coated with a thin poly-methyl methacrylate (PMMA) film (about $500 \mathrm{~nm}$ thicknesses) and consequently the underlying metal substrate is etched away in an appropriate solution, leaving a free-standing PMMA/graphene film. After rinsing with distilled water to remove the etching solvent, the PMMA/graphene layer is transferred easily, usually in liquid medium, onto any planar oxide substrate. Once the transfer is completed, the protective PMMA layer is removed by dissolution in acetone, leaving a graphene-coated oxide substrate. Since after the dissolving process traces of PMMA might remain on the graphene, it is suggested to anneal several hours under vacuum at temperatures around $300{ }^{\circ} \mathrm{C}$ for graphene surfaces with minimum contaminants. Through this method, graphene-coated $\mathrm{SiO}_{2}{ }^{[27-29]}$ and $\mathrm{ZnO}{ }^{[17,30,31]}$ samples among others, have been prepared and studied.

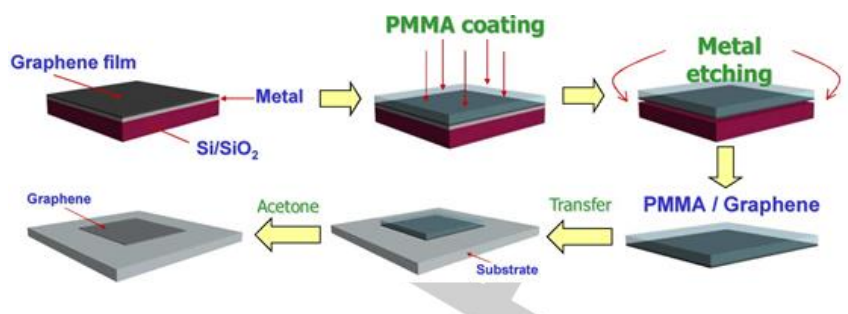

Figure 2. Schematic illustration of the graphene wet transfer process. From ${ }^{[26]}$.

Although the wet transfer method is relatively simple and easily reproducible, it has some considerable drawbacks. During the transfer the graphene layer often forms wrinkles and defects, while the residues of the protective PMMA layer are sometimes difficult to be completely removed. Thus, alternative methods which allow direct growth of graphene layer on oxide surfaces have been explored. For example, Peng et al. ${ }^{[32]}$ directly grew bilayer graphene on $\mathrm{SiO}_{2}$ substrates by carbon diffusion through a nickel layer, sandwiched between the oxide substrate and a polymer film. Annealing the sample (polymer film/400 nm Ni/300 $\mathrm{nm} \mathrm{SiO} / \mathrm{Si}$ ) at $1000{ }^{\circ} \mathrm{C}$ under low pressure $\mathrm{Ar} / \mathrm{H}_{2}$ conditions decomposes the polymer film and the remaining carbon dissolves into the nickel layer. After cooling down, graphene is formed on both sides of $\mathrm{Ni}$ from the precipitated carbon. Consequent dissolution and removal of the $\mathrm{Ni}$ layer produces a bi-layer graphene film directly deposited on the $\mathrm{SiO}_{2}$ substrate. In following works, this $\mathrm{Ni}$-assisted carbon diffusion method was applied using other carbon sources such as $\mathrm{CH}_{4}{ }^{[33]}, \mathrm{C}_{2} \mathrm{H}_{4}{ }^{[34]}$ nitrogen containing polymer ${ }^{[35]}$ and amorphous carbon ${ }^{[36,37]}$. Depending on the carbon source graphene was grown in different scale and layer thickness on $\mathrm{SiO}_{2}, \mathrm{Al}_{2} \mathrm{O}_{3}$ etc. Graphene has been also prepared through CVD method directly on various oxides surfaces, such as $\mathrm{MgO}^{[38-41]}, \mathrm{SiO}_{2}{ }^{[42,43]}, \mathrm{Al}_{2} \mathrm{O}_{3}{ }^{[44]}, \mathrm{ZrO}_{2}{ }^{[40]}$ and $\mathrm{HfO}_{2}{ }^{[45]}$, however in most of the cases this direct method produces graphene films with relatively poor quality.

\subsection{Metal oxide supports with complex morphology}

Graphene-coated oxides can be prepared through a simple electrostatic self-assembly strategy, using graphene oxide (GO) as a precursor ${ }^{[19,46,47]}$. Generally the fabrication process involves three steps, which are as follows: initially the surface of the metal oxide support material is modified/functionalized with cationic surfactants (which later act as molecular linkers), such as 3-aminopropyl triethoxysilane (APTES), Poly(allylamine hydrochloride) (PAH) etc.. In a second step the metal oxide is coated with GO layers through electrostatic attraction forces between the negatively charged GO and the positively charged metal oxide. Finally, the GO shell is reduced to form graphene. The reduction of $\mathrm{GO}$ layers can be performed either through a hydrothermal process ${ }^{[19]}$ or in a hydrazine $\left(\mathrm{N}_{2} \mathrm{H}_{4}\right)$ solution ${ }^{[46]}$. Because of its simplicity and efficiency, this method has been widely applied to coat metal oxides with various structures, such as $\mathrm{SnO}_{2}$ nanowires ${ }^{[46]}, \alpha-\mathrm{Fe}_{2} \mathrm{O}_{3}$ nanoparticles ${ }^{[46]}$, hollow $\mathrm{TiO}_{2}$ nanospheres ${ }^{[48]}$, and $\mathrm{SiO}_{2}$ nanoparticles ${ }^{[47]}$. Following a similar approach, Wang et al. [49] fabricated $\mathrm{GO}$ wrapped $\mathrm{Fe}_{2} \mathrm{O}_{3}$ nanocrystals with the assistance of chitosan. In this case 
hydrogen bonding and electrostatic interactions between the chitosan chains and the GO sheets were the driving force to assemble the GO with the metal oxide.
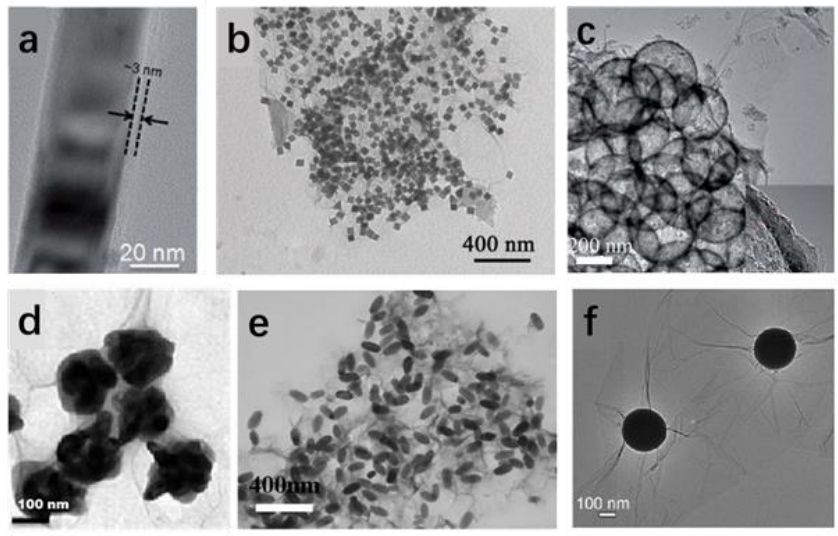

Figure 3. TEM images of oxides with various morphologies coated by graphene through electrostatic self-assembly strategy: (a) $\mathrm{SnO}_{2}$ nano wires ${ }^{[46]}$ (b) $\alpha-\mathrm{Fe}_{2} \mathrm{O}_{3}$ particles ${ }^{[50]}$, (c) hollow $\mathrm{TiO}_{2}$ spheres ${ }^{[48]}$, (d) $\alpha-\mathrm{Fe}_{2} \mathrm{O}_{3}$ particles ${ }^{[46]}$ (e) $\mathrm{Fe}_{2} \mathrm{O}_{3}$ particles ${ }^{[49]}$ and (f) $\mathrm{SiO}_{2}$ particles ${ }^{[47]}$.

A drawback of the above described fabrication method is that residuals of the molecular linkers, which are used to bind GO on the oxide supports, might remain after GO reduction and potentially influence the catalytic properties of the hybrid material. To overcome these problems Wei et al. ${ }^{[50,51]}$ proposed a facile room-temperature approach to prepare GO-wrapped metal oxides (e.g. $\mathrm{Fe}_{2} \mathrm{O}_{3}$ ) using metal cations instead of molecular linkers, as GO anchor sites. Generally, when the metal oxide nanoparticles (e.g. $\mathrm{Fe}_{2} \mathrm{O}_{3}$ ) are dispersed into a solution which contains the same metal cations (i.e. $\mathrm{Fe}^{3+}$ ), the metal cation will be absorbed on the surface of the metal oxide according to the Fajans rule to form positively-charged metal oxide particles ${ }^{[52]}$. When these positively-charged particles are mixed with a negatively-charged GO solution they will be covered by $\mathrm{GO}$ due to electrostatic interactions. This procedure is followed by a final reduction step of GO to form graphenecovered metal oxide particles. A selection of TEM images of various oxides coated with graphene using the electrostatic selfassembly fabrication method is given in Fig. 3. As shown in the TEM images, during synthesis the graphene oxide will follow the morphology of the oxide substrate by wrapping around its surface. This is a significant advantage of the electrostatic selfassembly method, since the morphology of the graphene-coated oxides can be well controlled through the designed structure of the oxide precursor.

Instead of coating GO onto metal oxide nanostructures through the two-steps solution mixing approach, Son et al. [53] demonstrated a direct, single-step, technique for the synthesis of $\mathrm{ZnO}-$ graphene quasi-core-shell quantum dots. As shown in the schematic of the chemical synthesis process presented in Fig. 4, initially zinc acetate dihydrate and GO are mixed together in dimethyl formamide (DMF) solution and the temperature is increased to $95{ }^{\circ} \mathrm{C}$, where the $\mathrm{ZnO}$ quantum dots are formed. Subsequently, $\mathrm{Zn}^{2+}$ ions in the solution are used as binders between $\mathrm{ZnO}$ quantum dots and $\mathrm{GO}$ layers, through a simple chemisorption process and/or by formation of $\mathrm{Zn}-\mathrm{O}-\mathrm{C}$ bonds. During this process, graphene can be peeled off layer-by-layer from the GO layers through the chemical force, and cover the $\mathrm{ZnO}$ quantum dots to form graphene-coated $\mathrm{ZnO}$ particles. A fundamental difference in this "soft" integration method as compared to the electrostatic self-assembly approach mentioned above, is that in the former the oxide particles are grown in situ and are coated by graphene oxides in the solution phase. Therefore in this case it is not the oxide support, but the graphene oxide, which plays the "structure-directing" role that defines the final composite material. ${ }^{[19,54]}$

Besides using GO precursor, the graphene coating layer on metal oxides can be also generated starting from other carbon sources. For example, Mendes et al. ${ }^{[55]}$ used oleic acid as a carbon source to form a few layer graphene coating on iron oxide nanoparticles (NPs). Two graphitization approaches were demonstrated in that work, either using electron beam irradiation or thermal annealing. The electron beam irradiation method was carried out in situ in a transmission electron microscope using low voltage electron beam $(80 \mathrm{keV})$. Alternatively, thermal annealing at $500{ }^{\circ} \mathrm{C}$ under high vacuum conditions $\left(\sim 10^{-6} \mathrm{mbar}\right)$ was sufficient to graphitize the oleic acid layer and form few layer graphene on iron oxide support. However, a side effect of thermal annealing is the partial reduction of iron oxide and the aggregation of the oxide nanoparticles, which might cause deactivation problems in catalytic applications.

\section{Graphene-coated metal oxides in catalytic applications}

\subsection{Graphene-coated metal oxides as photocatalysts}

The high charge carrier mobility and the transparency of graphene make it an excellent candidate material for photocatalytic applications. On the other hand, graphene displays a semi-metallic (or zero-gap semiconductor) character, which excludes its use as a stand-alone material in such applications. Combination of graphene with a semiconductor (composite material) can significantly enhance the lifetime of photo-generated electro-hole pairs and increase the charge transfer rate of electrons toward surface-adsorbed molecules during a photocatalytic process ${ }^{[18,56-58]}$. Besides of its role as an electron reservoir, graphene can also enhance the adsorption capacity ${ }^{[59,60]}$, extend the light absorption range ${ }^{[48,61]}$ and act as a macromolecular photosensitizer ${ }^{[62-64]}$. Therefore, in recent years, numerous attempts have been made to apply the graphene-semiconductor composite materials in the area of photocatalysis, some excellent reviews on this topic have been written recently ${ }^{[25,65-68]}$. However, a review that focuses on graphene-coated oxides needs to overview the role of graphene coating layers in the photocatalytic performance. Certainly the structure of graphene-based composites photocatalysts affects their behavior as has been demonstrated in several studies 
[60,64,66,69-71]. In the following part some typical examples are selected to highlight the superior performance of graphene coated oxides on photocatalytic reactions. a

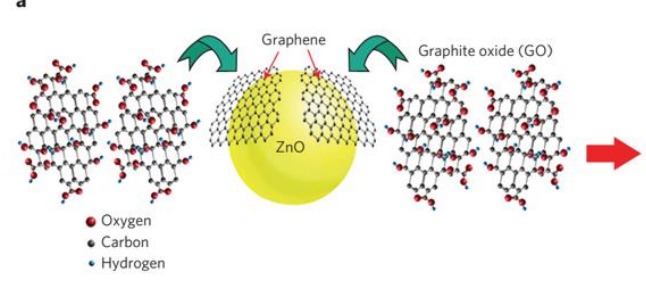

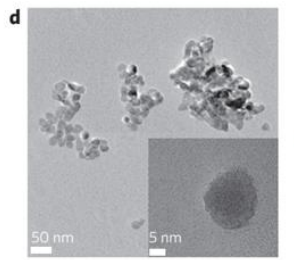
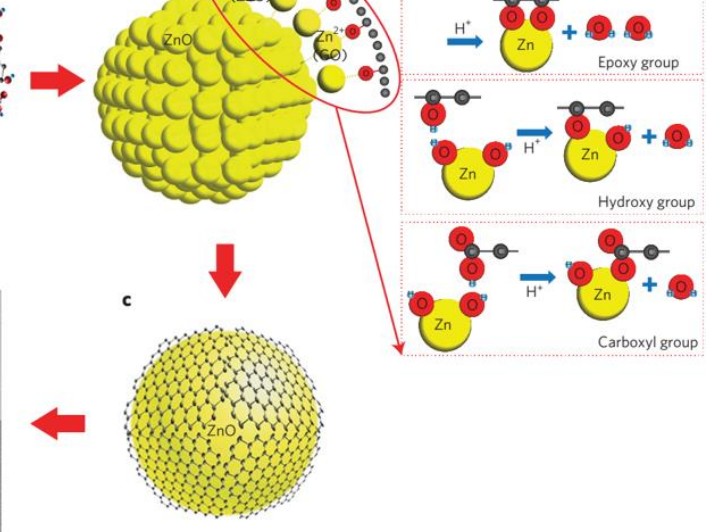

mo

Figure 3. Chemical synthesis process for the $\mathrm{ZnO}-$ graphene quasi-quantum dots and TEM image of the as prepared $\mathrm{ZnO}-g r a p h e n e$ quantum dots. From ${ }^{[53]}$

$\mathrm{TiO}_{2}$ is the most widely studied semiconductor photocatalyst due to its low cost, high chemical stability, non-toxicity, and resistance to photo-corrosion. However, due to an intrinsic large band gap (3.2 eV for anatase and $3.0 \mathrm{eV}$ for rutile phase), the photocatalytic activity of $\mathrm{TiO}_{2}$ is mainly restricted in the ultraviolet region. Several strategies have been proposed to extend the yield of visible light absorption of $\mathrm{TiO}_{2}$, such as doping with metals ${ }^{[72,73]}$ and non-metals ${ }^{[74,75]}$, as well as its combination with electron acceptor materials ${ }^{[76]}$. In the last few years, graphene has been explored as an electron acceptor material to prepare graphene- $\mathrm{TiO}_{2}$ hybrids with reduced band gap so as to enhance the photocatalytic performance. Various methods have been applied to prepare $\mathrm{TiO}_{2}$-graphene composite materials with different structures ${ }^{[16,76,77]}$. However, a "hard" integration of reduced graphene oxides with $\mathrm{TiO}_{2}$ nanoparticles did not show significant difference in the photocatalytic performance as compared to its carbon allotrope (such as carbon nanotubes) ${ }^{[60]}$. The enhanced photocatalytic activity of graphene- $\mathrm{TiO}_{2}$ composite materials can be attributed to their intimate interfacial contact, as in the case of graphene-coated $\mathrm{TiO}_{2}{ }^{[15,48,78]}$.

In order to study the effect of contact area between graphene and $\mathrm{TiO}_{2}$, Kim et al. ${ }^{[79]}$ prepared nanosized graphene oxidecoated $\mathrm{TiO}_{2}$ nanoparticles ( $\mathrm{r}$-NGOT) and compared their photocatalytic hydrogen generation performance with $\mathrm{TiO}_{2}$ nanoparticles supported on large size graphene oxide sheets ( $r$ LGOT). It was observed that the rates of $\mathrm{H}_{2}$ production and photocurrent generation in the case of r-NGOT were higher as compared to r-LGOT. This was attributed to the higher contact area between graphene and $\mathrm{TiO}_{2}$ in r-NGOT composites which facilitates the interfacial electron transfer. It is worth noting that, although more functional groups and defects in the NGOs precursor should reduce the conductivity, they can also serve as nuclear sites to combine with $\mathrm{TiO}_{2}$ nanoparticles forming core/shell structures. This ensures an intimate interfacial contact between graphene and oxide and enhances the photoelectrochemical performance.

In addition to the manipulation of the structure of graphene precursors, the properties of the $\mathrm{TiO}_{2}$ precursors also play a key role that affects the contact between $\mathrm{TiO}_{2}$ and graphene and consequently the photocatalytic performance. Recently, Lee et al. ${ }^{[18]}$ synthesized graphene-coated anatase $\mathrm{TiO}_{2}$ nanoparticles by a one-step $\mathrm{GO}$ reduction and amorphous $\mathrm{TiO}_{2}$ crystallization process via hydrothermal treatment and tested their photocatalytic performance in the degradation of methylene blue (MB). As compared to the bare anatase $\mathrm{TiO}_{2} \mathrm{NPs}$ and graphene coated crystalline anatase $\mathrm{TiO}_{2}$ NPs prepared by two-step hydrothermal method, the one step graphene- $\mathrm{TiO}_{2} \mathrm{NPs}$ showed a significantly reduced bandgap (2.8 eV instead of $3.2 \mathrm{eV}$ ) (see Fig. 5A), which was attributed to the direct interaction between carbon (from graphene) and $\mathrm{Ti}$ atoms on the $\mathrm{TiO}_{2} \mathrm{NP}$ surface. In this case, strong photocurrent response was recorded for graphene-wrapped $\mathrm{TiO}_{2}$ under visible irradiation for each switchon/off event, while no photocurrent was observed for both bare anatase $\mathrm{TiO}_{2} \quad \mathrm{NPS}$ and graphene-TiO 2 NPs (two-step hydrothermal) (see Fig. 5B). The authors suggested a mechanism to explain the photocatalytic degradation of $\mathrm{MB}$ over graphene- $\mathrm{TiO}_{2} \mathrm{NPs}$ under visible light irradiation (see Fig. 5C). They proposed that electrons from excited $\mathrm{MB}\left(\mathrm{MB}^{\star}\right)$ can flow to the conduction band of $\mathrm{TiO}_{2} \mathrm{NPS}$ via graphene, while at the same time, the valence electrons of $\mathrm{TiO}_{2}$ can be also excited to the conduction band state by absorbing visible light. These excited electrons convert the oxygen molecules to singlet oxygen which will oxidatively decompose MB through demethylation process. Meanwhile, the accelerated electron transfer from excited $\mathrm{MB}$ to $\mathrm{TiO}_{2}$ conduction band by graphene 
can hinder the recombination of excited electrons and improve the self-decomposition of MB.

Apart from $\mathrm{TiO}_{2}$ nanoparticles, the morphology of $\mathrm{TiO}_{2}$ can be also engineered to fabricate graphene- $\mathrm{TiO}_{2}$ composite with coreshell structure. Zhang et al. ${ }^{[48]}$ investigated the photocatalytic activity of graphene-encapsulated hollow $\mathrm{TiO}_{2}$ nanospheres for degradation of rhodamine $\mathrm{B}(\mathrm{RhB})$ under UV light irradiation and found excellent photocatalytic activity. This was attributed to the effect of graphene to promote the electron transfer from the inner hollow $\mathrm{TiO}_{2}$ to the outer graphene shells, and substantially suppress the recombination of photo-excited electrons and holes. Very recently, Lee et al. ${ }^{[80]}$ prepared graphene and palladium nanoparticles (Pd NPs) encapsulated titanium dioxide $\left(\mathrm{TiO}_{2}\right)$ composite nanowires and tested their photocatalytic activities. Under visible light irradiation, this material converted nearly $100 \%$ of 4-nitrophenol. The UV-vis spectrophotometry study showed that coated $\mathrm{TiO}_{2}$ nanowires resulted in a lowered band gap $(2.0 \mathrm{eV})$ as compared to that of pristine $\mathrm{TiO}_{2}$ nanowires (2.9 $\mathrm{eV}$ ) which induced much stronger visible light absorption.

Besides $\mathrm{TiO}_{2}$, another oxide which has been extensively studied as photocatalyst is $\mathrm{ZnO}$. In recent years, graphene-coated $\mathrm{ZnO}$ materials have been reported as efficient photocatalysts for decomposition of pollutants in water. For example, Bu et al. ${ }^{[81]}$ prepared graphene-ZnO quasi-shell-core composite materials by following the method described of Son et al. ${ }^{[53]}$ and investigated their photocatalytic efficiency for degradation of $\mathrm{RhB}$ and their photoelectrochemical performance. They showed that the amount of graphene in the graphene- $\mathrm{ZnO}$ composite is critical in both photocatalytic and photoelectrochemical processes. Furthermore, they proposed a mechanism for the improved catalytic performance of the graphene-ZnO quasishell-core composite material. Similar to graphene- $\mathrm{TiO}_{2}$ hybrids, the graphene coating can effectively reduce the transfer resistance of the photo-generated electrons and at the same time inhibits their recombination with holes. Moreover, the close contact of graphene with $\mathrm{ZnO}$ will positively shift the Fermi level of the latter, forming an interfacial electric field at the graphene$\mathrm{ZnO}$ interface. This electric field will further improve the separation efficiency of photo-induced electron-hole pairs resulting to an enhanced photocatalytic activity. In addition to the role of a photoelectron mediator, graphene coating on $\mathrm{ZnO}$ also exhibit an enhanced dye-adsorption ${ }^{[59,82]}$ and light absorption ${ }^{[19]}$ capability which in turn improves the photo degradation performance.

Apart from the above mentioned activity studies on graphene coated oxides, the photostability of these catalysts is another important issue that has been investigated. $\mathrm{ZnO}$ is widely accepted to suffer from the photo-corrosion under UV light, which significantly decreases its photocatalytic activity and limits its application in photocatalysis ${ }^{[19,83]}$. The photostability of $\mathrm{ZnO}$ can be greatly enhanced by coating a graphene layer on its surface, as shown by successive recycling tests of RhB degradation ${ }^{[19]}$. This is also in agreement with reports from photoelectrochemical $\mathrm{RhB}$ degradation experiments where graphene and $\mathrm{ZnO}$ formed a quasi-shell-core structure ${ }^{[81]}$. The high stability of graphene coated $\mathrm{ZnO}$ can be attributed to two main reasons, the first being the close contact between graphene and $\mathrm{ZnO}$ which works as a protection layer for the $\mathrm{ZnO}$ surface preventing the photocorrosion of $\mathrm{ZnO}$. ${ }^{[19]}$ The second reason is the fast consumption of photogenerated holes by the surface adsorbed RhB molecules, which inhibits the corrosion of $\mathrm{ZnO}{ }^{[19,81]}$.

The degradation of graphene caused by the oxidation of $\cdot \mathrm{OH}$ radicals, which are formed by the reaction of photogenerated holes and the surrounding water/hydroxyl species, has been observed on graphene-oxide composites photocatalysts [66,84]. On the contrary, no degradation of graphene has been reported in the graphene (reduced) coated oxide systems after recycling tests. ${ }^{[19,81]}$ Although further and systematic studies on the stability of graphene are still needed, the stability of graphene in graphene-coated oxide composites as compared to grapheneoxide ones, can be attributed to the appropriate interfacial interaction between the graphene layer and the oxide support, as well as the effective consumption of $\cdot \mathrm{OH}$ radicals by the reactants. ${ }^{[66]}$ 
A
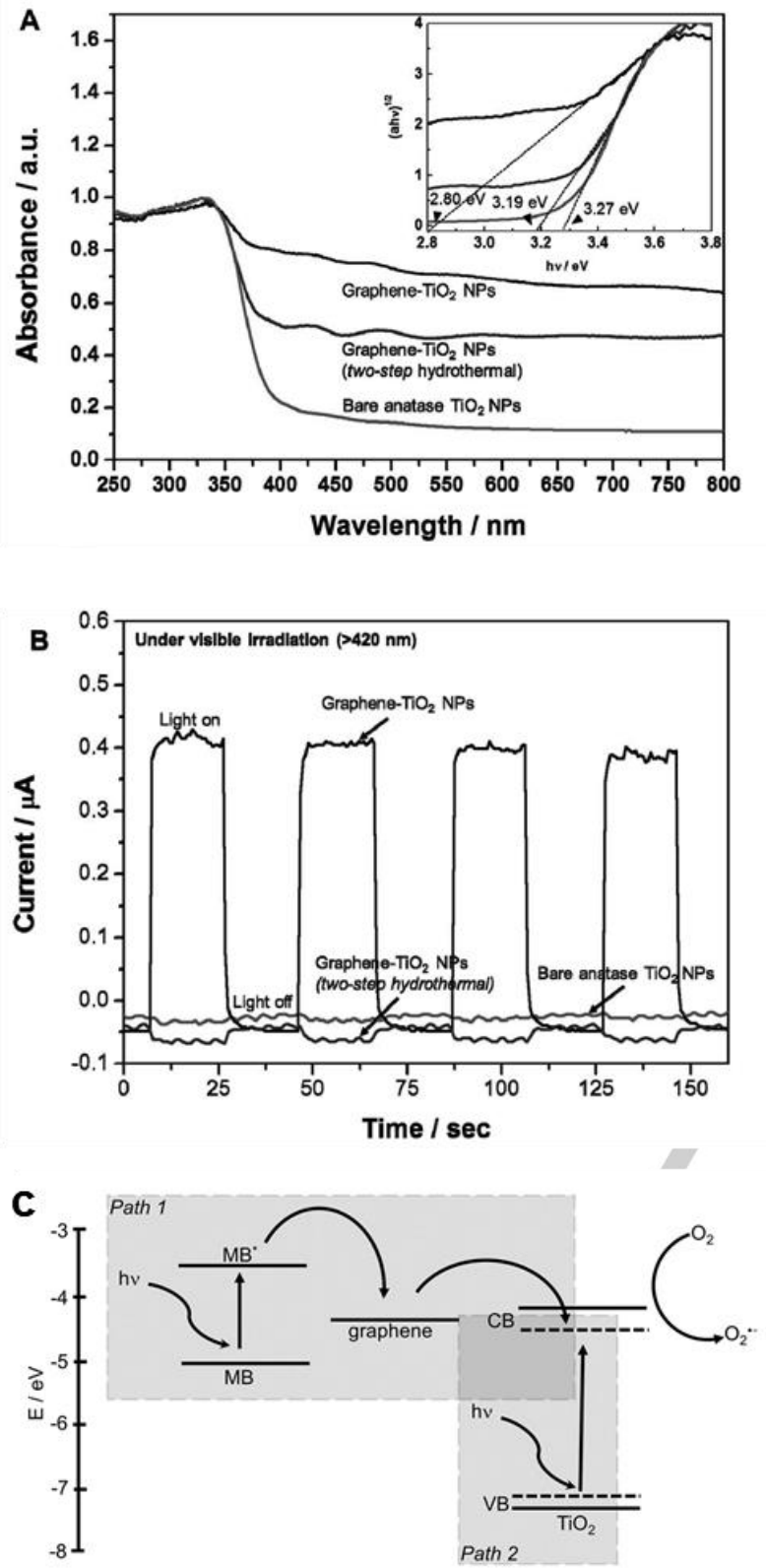

Figure 5. UV-visible spectra (A) and photocurrent response (B) of bare anatase $\mathrm{TiO}_{2}$ NPs, graphene $\mathrm{TiO}_{2}$ NPs, and graphene- $\mathrm{TiO}_{2}$ NPs (two-step hydrothermal). (C) Illustration of the photocatalytic mechanism of graphenewrapped anatase $\mathrm{TiO}_{2} \mathrm{NPS}$ for the degradation of $\mathrm{MB}$ under visible light. Reproduced from ref. ${ }^{[18]}$.

As such, we can see that the graphene-semiconductor oxide composites with core-shell structures can be fabricated with various synthesis methods and different types of precursors which are able to sufficiently strengthen the interfacial interaction between graphene and oxides. The significantly improved photocatalytic activity was attributed to the important role of graphene, which not only performs as a conductive medium for accepting and transporting photoelectrons, but also tunes the light absorption range and enhances the reactant adsorption capacity. Moreover, both the graphene coating layer and the semiconductor oxides show high photostability. Although, up to now, the most widely used precursors are $\mathrm{GO}, \mathrm{TiO}_{2}$ and $\mathrm{ZnO}$, shell-core composites of graphene with other semiconductor oxides may be a promising route to build a new class of catalysts with high photocatalytic performance.

\subsection{Graphene-coated metal oxides as other heterogeneous catalysts}

Graphene (assuming no defect sites) is a chemically inert material therefore it can be used as a coating to increase the resistance of metal oxides in harsh chemical environments. Very recently, Wei et al. ${ }^{[85]}$ prepared porous nitrogen-doped graphene-coated cobalt oxide catalysts $\left(\mathrm{CoO}_{x} @ \mathrm{CN}\right)$ and tested them in the hydrogenation of quinoline compounds. Their results indicated an excellent catalytic activity and good stability of $\mathrm{CoO}_{x} @ \mathrm{CN}$ in this reaction. This was attributed to the effect of the graphene coating layer, which effectively reduces the extent of leaching of cobalt from $\mathrm{CoO}_{x}$ nanoparticles while at the same time it protects them from agglomeration. In addition, the large surface area and the porous structure of the carbon layer ensure the facile diffusion of reactants and products in order to reach the catalytic sites. Besides, the graphene coating weakens the strong coordination between the $\mathrm{N}$-heterocycle and active metal nanoparticles and prolongs the catalyst lifetime.

Another case of catalytic performance improvement was found for nitrogen-doped graphene coating over $\mathrm{Fe}_{2} \mathrm{O}_{3}$. The catalysts were prepared by pyrolysis of iron-phenanthroline complexes on carbon and tested for hydrogenation of nitrobenzene in a watertetrahydrofuran (THF) solvent mixture ${ }^{[86]}$. Catalysts pyrolyzed at $800{ }^{\circ} \mathrm{C}$ (Fe-phen/C-800) showed maximum activity and selectivity towards the desired product (aniline), as compared to catalysts pyrolized at lower $\left(400{ }^{\circ} \mathrm{C}\right)$ or higher $\left(1000{ }^{\circ} \mathrm{C}\right)$ temperatures. HR-TEM characterization of the Fe-phen/C-800 showed that the active catalyst consists of iron oxide particles surrounded by a shell of 3 to 5 nitrogen-doped graphene layers (Fig. 6a). When the pyrolysis temperature is raised to $1000^{\circ} \mathrm{C}$, the less active iron oxide particles are coated by a much thicker (10- to $40 \mathrm{~nm}$ ) graphite layer (Fig. 6a). X-ray photoelectron spectroscopy (XPS) analysis was used to differentiate the various nitrogen species on the surface of the catalysts. As shown in Fig. 6b, the $\mathrm{N}$ 1s spectrum of the most active Fephen/C-800 catalyst indicate 3 types of nitrogen species which are assigned to pyridinic nitrogen, Fe- $\mathrm{N}$ centers and nitrogen in a graphite-like structure. The $\mathrm{N}$ 1s peak originating from the Fe$\mathrm{N}$ species disappears in the less active sample (after pyrolysis at $1000^{\circ} \mathrm{C}$ ) and is replaced by graphitic- $\mathrm{N}$, which made the authors to propose that the high catalytic activity is mainly related to the number of the Fe-N centers. ${ }^{[86]}$ 

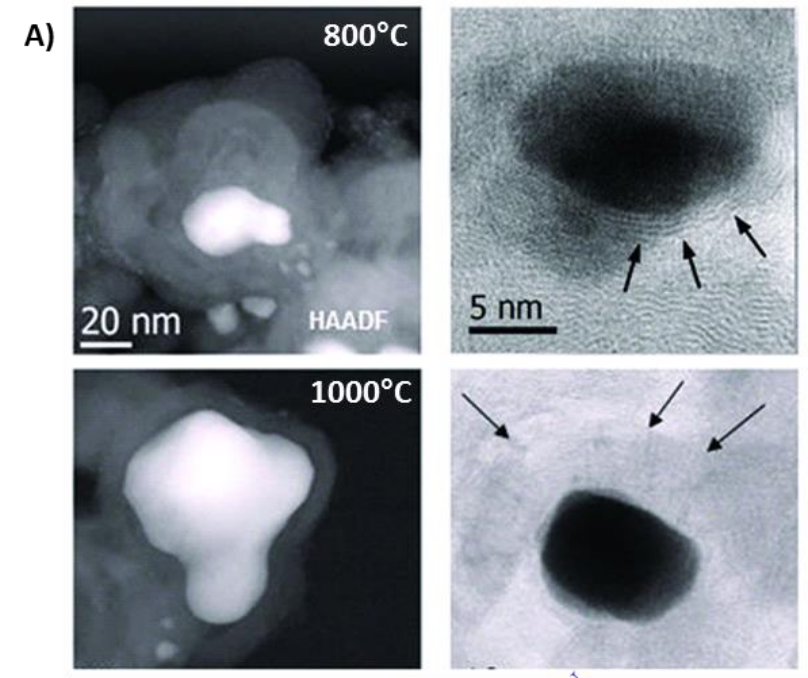

B)

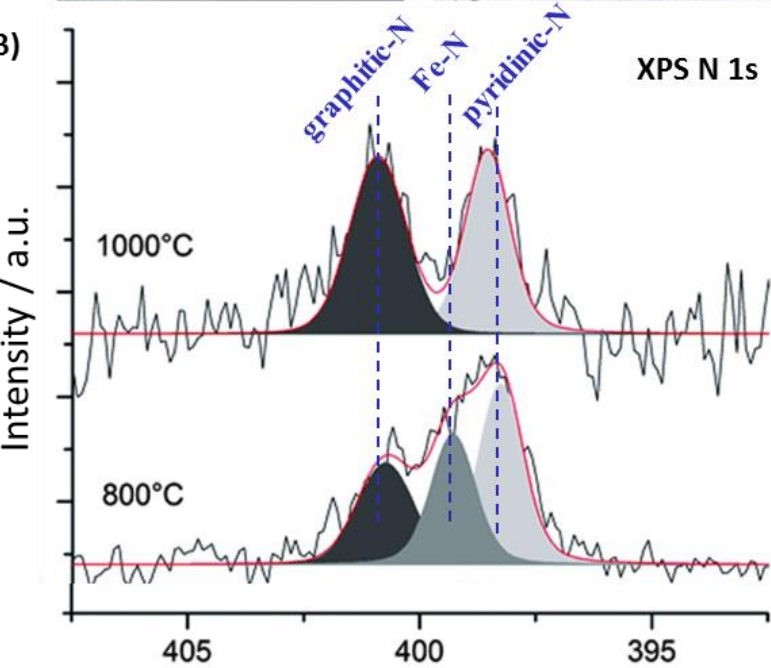

Electron Binding Energy / eV and of non-porous graphene-CoO (GE-CoO). Electrochemical capacitance measurements and electrical impedance spectroscopy results indicated that the PEG-CoO catalyst exhibited larger active surface area and lower charge transfer resistance, which were attributed to its superior electrocatalytic performance. Compared with GE-CoO, the PGE-CoO hybrid showed excellent durability in a $0.1 \mathrm{M}$ alkaline solution, as shown in Fig. 7e. This was ascribed to the advantage of the wrapped structure, where $\mathrm{CoO}$ nanoparticles are well confined by porous graphene, which prevents $\mathrm{CoO}$ from aggregation and corrosion. Moreover, in such a structure, the strong interaction and synergistic effect between $\mathrm{CoO}$ and porous graphene also play an important role on the high OER of PGE-CoO.
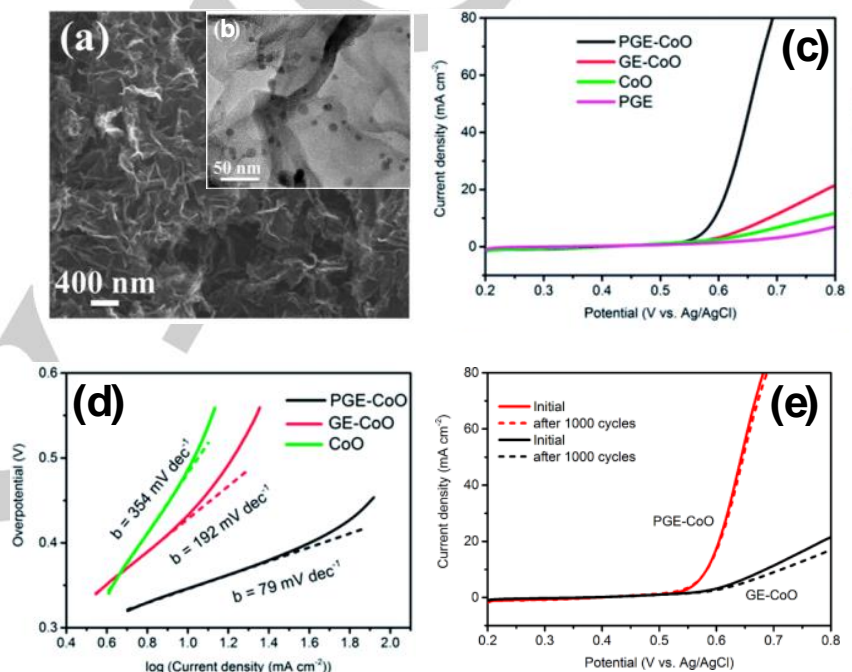

Figure 7. (a) SEM image of PGE, (b) TEM images of PGE-CoO, (c) polarization curves for PGE-CoO, GE-CoO, CoO and PGE in $0.1 \mathrm{M} \mathrm{KOH}$, (d) Tafel curves of PGE-CoO, GE-CoO and $\mathrm{CoO}$ in $0.1 \mathrm{M} \mathrm{KOH}$, and (e) The stability of PGE-CoO and GE-CoO modified electrodes before and after linear sweep voltammetry testing for 1000 cycles. Adapt from reference ${ }^{[88]}$.

With the selected examples, we can see that, besides photocatalysis, graphene coated oxides find applications also in several heterogeneous catalytic reactions. In the latter case, the nature of the oxide support can be varied and is not limited to semiconductors, as in the case of photocatalysts. This opens several new routes not only for the applications but also in the diversity of the preparation methods. However, one should keep in mind that the synergistic effect between graphene and oxides plays an important role in the activity and stability performance, independent of the choice of the oxide support.

\subsection{Graphene-coated oxides as catalytic supports}

Heterogeneous catalysts typically consist of one or more active metals dispersed on a support. The choice of the most appropriate catalytic support is based on diverse criteria, such as low cost, good mechanical properties and high surface area. Oxides like $\mathrm{SiO}_{2}, \mathrm{Al}_{2} \mathrm{O}_{3}, \mathrm{TiO}_{2}$ and $\mathrm{ZnO}$, are the most commonly

used support materials in heterogeneous catalysis. Their (OER). The activity tests showed that PEG-CoO displayed much higher OER activity than both its constituents (CoO and PGE) 
primary function is to improve the dispersion of the active metal sites, enhance their stability (chemical and structural), but in some cases they also participate in the reaction. However, some oxide supports, especially easily reducible oxides notably $\mathrm{TiO}_{2}$ or $\mathrm{ZnO}$, may also cause the deactivation of the catalyst under certain conditions. This can take place through strong interactions with metals, for example, by encapsulation of the active centers or oxidation of the metals and formation of inert mixed-oxide compounds ${ }^{[89,90]}$. Recently the idea to cover oxides with carbon in order to improve their stability, and consequently their performance, has attracted a lot of attention. In the graphitic form, carbon has been used to increase the stability of $\mathrm{Al}_{2} \mathrm{O}_{3}$ in biomass conversion reactions ${ }^{[1]}$, while more stable catalytic particles are formed over carbon-coated silica as compared to the uncovered one ${ }^{[92,93]}$. In spite of the increased interest on carbon-coated oxides, graphene coating on oxide supports has been only explored in model planar catalytic systems, which will be summarized below.

In one of these studies single-layer graphene was applied over single crystal $\mathrm{ZnO}$ (0001) planar surfaces and its effect on cobalt NPs, grown by thermal evaporation in vacuum, was studied ${ }^{[17]}$. Interestingly it was shown that when a graphene layer was inserted between cobalt particles and the oxide substrate, the morphology and the oxidation/reduction properties of cobalt was modified. As shown by the Co $2 \mathrm{p}_{3 / 2}$ XPS spectra in Fig. 8, after annealing under UHV conditions cobalt supported on graphenecoated $\mathrm{ZnO}$ could maintain the metallic state till $350{ }^{\circ} \mathrm{C}$ (Fig. 8b). Contrarily, without the graphene layer Co was readily oxidized to
$\mathrm{CoO}$ (Fig. 8a) presumably through a solid state interface interaction with the $\mathrm{ZnO}$ support, as indicated later by angleresolved XPS spectra ${ }^{[31]}$. In a more recent study, it was shown that graphene layer also weakens the interactions between Co and $\mathrm{SiO}_{2}$, even if $\mathrm{SiO}_{2}$ is considered as a relatively inert substrate as compared to $\mathrm{ZnO}{ }^{[30,31]}$. Moreover, the interaction between $\mathrm{Co}$ and graphene dictates not only the oxidation state but also the particles size of cobalt. In particular at low temperature graphene improves the dispersion of cobalt as compared to oxide substrates, while upon annealing it provokes particle agglomeration leading to bigger cobalt particle size.

Apart from the metal-support interface interaction, graphene can also influence the oxidation/reduction properties of cobalt nanoparticles supported on coated oxides $\left(\mathrm{ZnO}\right.$ and $\left.\mathrm{SiO}_{2}\right)$ under low $\left(10^{-7} \mathrm{mbar}\right)$ and medium $(7 \mathrm{mbar})$ pressure $\mathrm{O}_{2} / \mathrm{H}_{2}$ environment ${ }^{[30,31]}$. In particular, under low pressure $\mathrm{O}_{2}$ the oxidation of Co supported on graphene-coated $\mathrm{ZnO}$ and $\mathrm{SiO}_{2}$ substrates was limited [31], as compared to cobalt directly attached on the oxide support. However, when the $\mathrm{O}_{2}$ pressure increases to the mbar range the differences between cobalt supported on bare and graphene-coated oxides fade. This observation was explained by the differences induced by graphene on the cobalt particles size. Specifically, in mild oxidation conditions, large cobalt particles (in the range of $20 \mathrm{~nm}$ ) are preferentially oxidized on their surface leaving the particle core in the metallic state due to oxygen diffusion limitations. When the particles are considerably smaller, or more flat, they are totally oxidized (Fig. 8c).
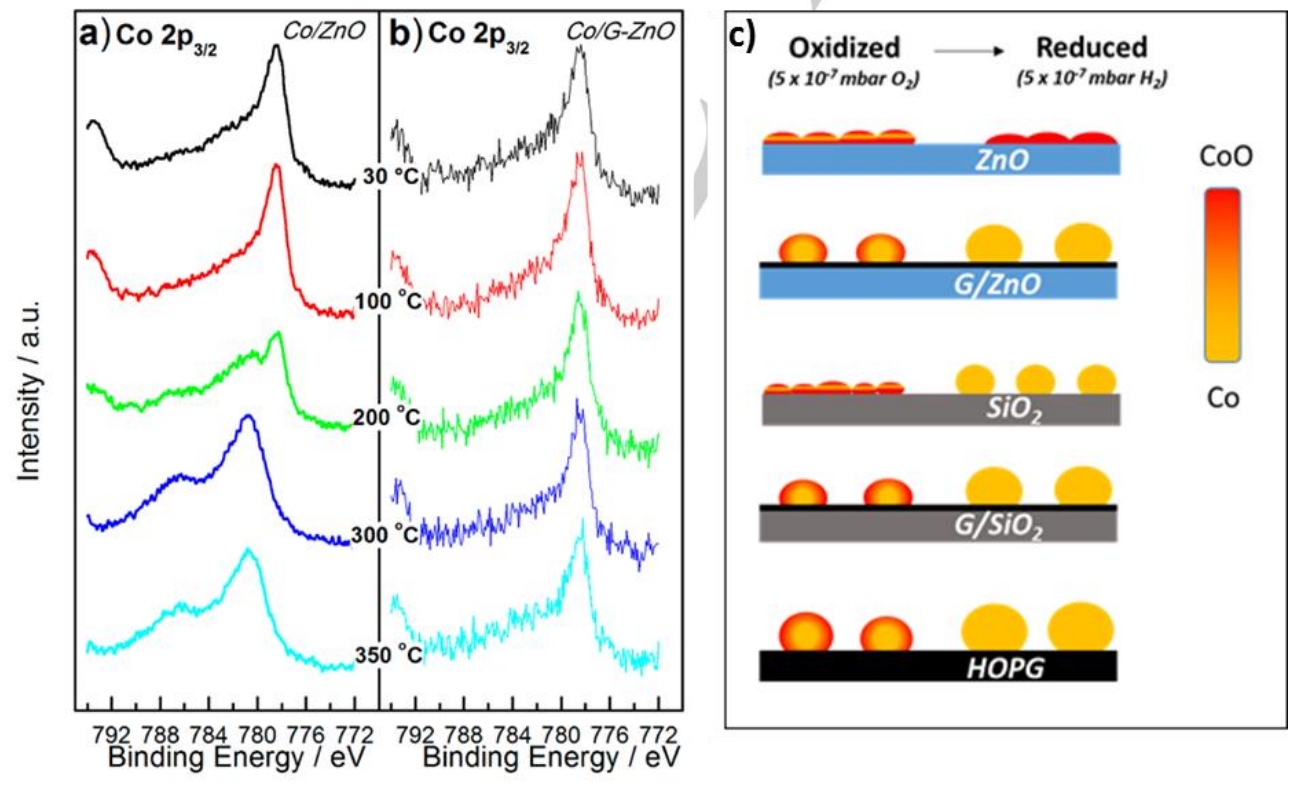

Figure 8. XPS spectra of (a) $\mathrm{Co} / \mathrm{ZnO}$ and (b) $\mathrm{Co} / \mathrm{G}-\mathrm{ZnO}$ upon annealing at different temperatures under UHV conditions. (c) Schematic representation of the particle size and the oxidation state of cobalt particles upon annealing in $\mathrm{O}_{2}$ and $\mathrm{H}_{2}$ environments. Adapted from references ${ }^{[19,30]}$.

The reduction of cobalt oxide particles under low and medium pressure $\mathrm{H}_{2}$ conditions was dramatically promoted by the graphene layer, leading to cobalt reduction at significantly lower temperatures. Angle resolved XPS measurements indicate that this is mainly a consequence of the restriction of Co NPs interaction with the oxide supports ${ }^{[31]}$. Moreover, at high temperature graphene protects $\mathrm{Co}$ from the formation of mixed $\mathrm{Co}_{x} \mathrm{Zn}_{1-\mathrm{x}} \mathrm{O}_{2}$ compounds ${ }^{[30]}$, which are more difficult to reduce 
than cobalt oxides $\left(\mathrm{CoO}\right.$ or $\left.\mathrm{Co}_{3} \mathrm{O}_{4}\right)$. It is interesting to note that the graphene-supported cobalt particles show differences in morphology as compared to graphite supported ones. This suggests that the cobalt-graphite interaction is weaker than that of graphene, therefore cobalt surface diffusion and agglomeration to form bigger particles is favored on graphite. Based on this finding it is suggested that graphene and graphitecoated oxides might influence the supported particles in a different way and therefore it is of particular interest to control the number of graphene layers over the oxide. ${ }^{[1]}$

\subsection{Stability of oxide-supported single layer graphene in reactive environments}

A crucial issue for practical applications is definitely the stability of graphene-coated oxides under harsh catalytic reaction environments. Raman studies can give a relatively accurate report about the number and the nature of the defects induced on the graphene layer under reactive environments. Fig. 9a shows Raman spectra of graphene-covered $\mathrm{SiO}_{2}$ supports before and after cobalt deposition as well as after an oxidation/reduction cycle in $7 \mathrm{mbar}_{2}$ and $\mathrm{H}_{2}$ at temperatures up to $400{ }^{\circ} \mathrm{C}{ }^{[30]}$. The $\mathrm{G}$ band at $1580 \mathrm{~cm}^{-1}$ and the $2 \mathrm{D}$ band at $\sim 2700 \mathrm{~cm}^{-1}$ are due to the in-plane vibrational $\left(E_{2 g}\right)$ mode and the two phonon intervalley double resonance scattering of graphene ${ }^{[94,95]}$, respectively. The narrow symmetric 2D band and the relatively low $\mathrm{G} / 2 \mathrm{D}$ bands intensity ratio can be used as safe indicators of single-layer graphene ${ }^{[94]}$. After cobalt deposition and prior to any treatment, two additional features at $\sim 1350 \mathrm{~cm}^{-1}$ and $1625 \mathrm{~cm}^{-1}$ appear in the Raman spectrum (Fig. 9a). The peak at $1350 \mathrm{~cm}^{-1}$ is assigned to the $D$ band and is activated due to a single-phonon intervalley process caused by defects in the graphene lattice (edges, vacancies etc.). The other one, known as D' band, is activated by an intravalley scattering process which also requires defects. In addition to the appearance of the D and D' bands, after Co deposition both the $G$ and $2 \mathrm{D}$ bands become slightly broader due to graphene disorder ${ }^{[96]}$. It is therefore evident that vacuum deposition of cobalt $(0.8 \mathrm{~nm})$ at room temperature forms defects on the graphene layer. This observation suggests that Co plays a catalytic role on the introduction of defects in graphene.

The Raman spectra of $\mathrm{Co} / \mathrm{G} / \mathrm{SiO}_{2}$ after redox treatments show more intense $D$ and $D^{\prime}$ ' bands indicating highly defective graphene. Spectra from different sample regions, notably bilayer-graphene island (abbreviated as $\mathrm{BL}-\mathrm{Co} / \mathrm{G} / \mathrm{SiO}_{2}$ ) and graphene areas at the corner of the sample, which were protected from cobalt deposition by the mounting clip (abbreviated as $\mathrm{G} / \mathrm{SiO}_{2}$ ), are included in the same figure. The different regions are indicated in the optical images of the samples shown in Fig. 9b. After analysis of the Raman spectra it was found that the defect density of graphene after the redox treatment increases considerably on single layer areas, while the bilayer graphene areas or areas without cobalt, were proved to be much more resistant with lower defect sites.

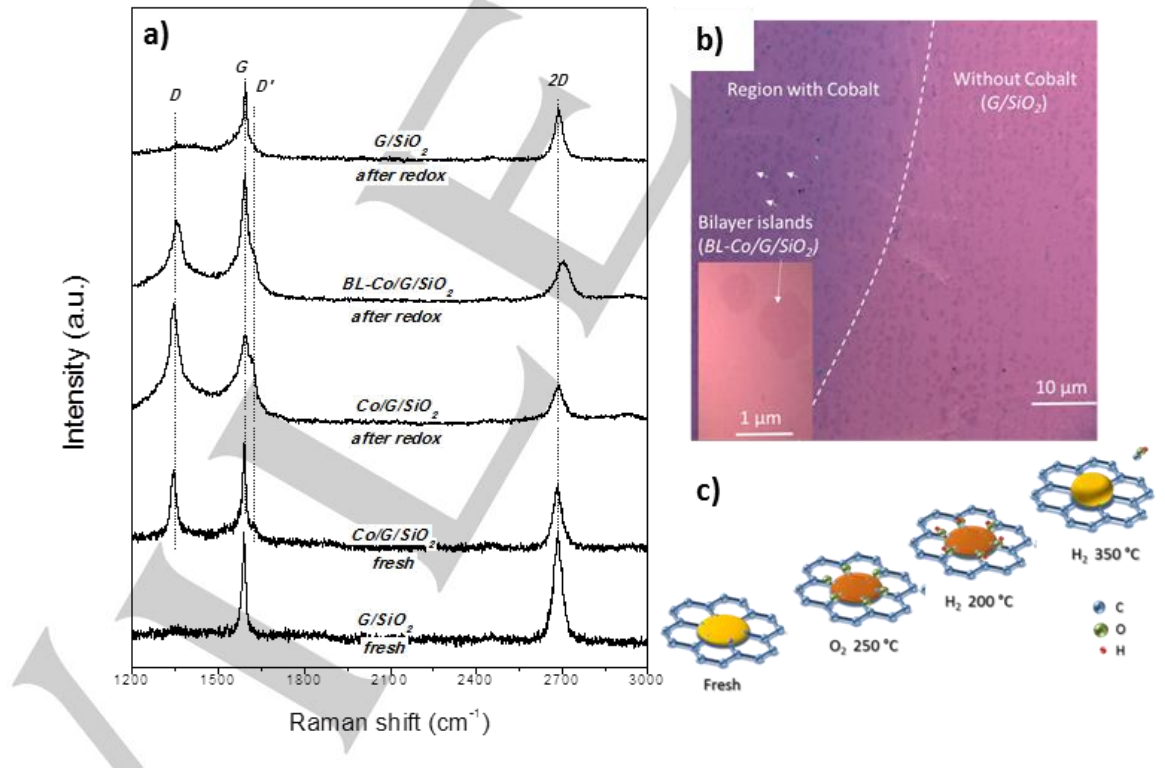

Figure 9. (a) Raman spectra recorded over graphene-covered $\mathrm{SiO}_{2}$ before and after $0.8 \mathrm{~nm}$ cobalt deposition as well as after $7 \mathrm{mbar} \mathrm{O}_{2}$ and $\mathrm{H}_{2}$ treatments up to $400{ }^{\circ} \mathrm{C}$. In the latter case Raman spectra were recorded at different sample regions as shown in (b) the optical image. (c) Schematic representation of the proposed mechanism of the formation of graphene defects in contact with cobalt during the redox treatment. Adapted from ${ }^{\text {[30] }}$.

By combining Raman and XPS results, a mechanism of graphene quality deterioration over cobalt covered areas was described (Fig. 9c). XPS results gave evidence of a chemical interaction at the Co-graphene interface through a carbon dissolution-precipitation mechanism. This interaction is likely accountable for the formation of local defects on graphene in contact with cobalt and can be possibly enhanced with temperature ${ }^{[97]}$. The carbon atoms of graphene lattice which are 
locally diluted in cobalt particles are vulnerable to oxidation in $\mathrm{O}_{2}$ atmosphere. When the gas atmosphere switch to $\mathrm{H}_{2}$, oxidized carbon species transform to volatile $\mathrm{C}-\mathrm{O}$ and/or $\mathrm{C}-\mathrm{O}-\mathrm{H}$ compounds, leaving behind defective graphene layer in the vicinity of cobalt particles. This mechanism is consistent with the observation of highly defective graphene only in cobalt coved areas of graphene $\left(\mathrm{Co} / \mathrm{G} / \mathrm{SiO}_{2}\right)$ but not on areas without $\mathrm{Co}$ $\left(\mathrm{G} / \mathrm{SiO}_{2}\right)$.

\section{Conclusion and perspectives}

In summary, graphene-coated metal oxides have attracted great interest in catalysis research, mainly due to their promising applications as photo- and heterogeneous catalysts. Moreover, studies on model systems proposed that graphene has a great potential as support modifier in heterogeneous catalytic reactions, especially when the interaction between metal and the support has to be moderated. In recent years, various methods to produce graphene with high quality and/or large scale have been proposed including mechanical exfoliation, chemical exfoliation, chemical vapor deposition, epitaxial growth etc. In addition, a variety of synthetic strategies such as wet transfer, electrostatic self-assembly synthesis and chemical vapor deposition, have been developed for fabricating graphenecoated oxides both for models and realistic catalytic systems. Scale up production of these strategies is important to promote industrial applications of graphene-coated metal oxides.

Many studies have shown that graphene coating significantly modifies the metal/oxide synergy and consequently the catalytic performance. Although graphene can be an efficient mediator of the metal-support interactions, it has a minimal footprint in the macroscopic metal oxide characteristics. In photocatalysis, graphene-coated semiconductor oxides, in particular $\mathrm{TiO}_{2}$ and $\mathrm{ZnO}$, have shown their great potential in environmental and energy-related applications. Nevertheless, homogeneous coating with controllable graphene thickness remains a challenge that has to be faced to enable the full potential of these materials. Since graphene properties are strongly dependent on the number of layers, development of new methods to prepare high quality graphene-coated oxides is required.

The stability of graphene might be an issue, since under the catalytic reaction conditions graphene quality deteriorates and defective graphene sites are formed. However, defects on graphene can also act as anchor sites for metal particles or for dopants and even as active sites for reactions. Therefore, defect formation should be further studied considering that modification of graphene and formation of defects might be deliberately performed for some applications. These findings might help to design supported metal catalysts with enhanced stability by coating a layer of graphene on the oxide support. To achieve high performance graphene-based catalysts, it is essential to control in the highest possible degree both graphene properties and structures. This should be taken into account in the recent effort to develop better heterogeneous catalysts and move from the typically used amorphous or graphitic multilayer carbon oxide coatings to single or few layer graphene.

Keywords: oxides $\bullet$ graphene $\cdot$ coat $\bullet$ catalyst $\bullet$

[1] K. S. Novoselov, A. K. Geim, S. V Morozov, D. Jiang, Y. Zhang, S. V Dubonos, I. V Grigorieva, A. A. Firsov, Science 2004, 306, 666669

[2] S. V. Morozov, K. S. Novoselov, M. I. Katsnelson, F. Schedin, D. C. Elias, J. A. Jaszczak, A. K. Geim, Phys. Rev. Lett. 2008, 100, 11-14.

[3] J.-H. Chen, C. Jang, S. Xiao, M. Ishigami, M. S. Fuhrer, Nat. Nanotechnol. 2008, 3, 206-209.

[4] A. A. Balandin, S. Ghosh, W. Bao, I. Calizo, D. Teweldebrhan, F. Miao, C. N. Lau, Nano Lett. 2008, 8, 902-907.

[5] S. Stankovich, D. A. Dikin, G. H. Dommett, K. M. Kohlhaas, E. J. Zimney, E. A. Stach, R. D. Piner, S. T. Nguyen, R. S. Ruoff, Nature 2006, 442, 282-286.

[6] R. R. Nair, P. Blake, A. N. Grigorenko, K. S. Novoselov, T. J. Booth, T. Stauber, N. M. R. Peres, A. K. Geim, Science 2008, 320, 1308

[7] L. Qu, Y. Liu, J. B. Baek, L. Dai, ACS Nano 2010, 4, 1321-1326.

[8] Z. Yang, Z. Yao, G. Li, G. Fang, H. Nie, Z. Liu, X. Zhou, X. Chen, S. Huang, ACS Nano 2012, 6, 205-211.

[9] Y. Xue, D. Yu, L. Dai, R. Wang, D. Li, A. Roy, F. Lu, H. Chen, Y. Liu, J. Qu, Phys. Chem. Chem. Phys. 2013, 15, 12220-12226.

[10] R. Kou, Y. Shao, D. Wang, M. H. Engelhard, J. H. Kwak, J. Wang, V. V. Viswanathan, C. Wang, Y. Lin, Y. Wang, et al., Electrochem. commun. 2009, 11, 954-957.

[11] A. Y. Khodakov, W. Chu, P. Fongarland, Chem. Rev. 2007, 107, 1692-1744.

[12] G. L. Bezemer, J. H. Bitter, H. P. C. E. Kuipers, H. Oosterbeek, J. E. Holewijn, X. Xu, F. Kapteijn, A. J. Van Dillen, K. P. De Jong, J. Am. Chem. Soc. 2006, 128, 3956-3964.

[13] Y. T. Law, W. H. Doh, W. Luo, S. Zafeiratos, J. Mol. Catal. A Chem 2014, 381, 89-98.

[14] S. Turczyniak, W. Luo, V. Papaefthimiou, N. S. Ramgir, M. Haevecker, A. Machocki, S. Zafeiratos, Top. Catal. 2015, 5, 532542

[15] T. Kamegawa, D. Yamahana, H. Yamashita, J. Phys. Chem. C 2010 114, 15049-15053.

[16] G. Williams, B. Seger, P. Kamat, ACS Nano 2008, 2, 1487-1491.

[17] W. Luo, W. H. Doh, Y. T. Law, F. Aweke, A. Ksiazek-Sobieszek, A. Sobieszek, L. Salamacha, K. Skrzypiec, A. Machocki, S. Zafeiratos, et al., J. Phys. Chem. Lett. 2014, 5, 1837-1844.

[18] J. S. Lee, K. H. You, C. B. Park, Adv. Mater. 2012, 24, 1084-1088.

[19] B. Weng, M. Q. Yang, N. Zhang, Y. J. Xu, J. Mater. Chem. A 2014, 2, 9380-9389.

[20] B. F. Machado, P. Serp, Catal. Sci. Technol. 2012, 2, 54-75.

[21] D. Chen, L. Tang, J. Li, Chem. Soc. Rev. 2010, 39, 3157-3180

[22] D. Haag, H. H. Kung, Top. Catal. 2014, 57, 762-773.

[23] X. Zhou, J. Qiao, L. Yang, J. Zhang, Adv. Energy Mater. 2014, 4, 1301523.

[24] N. M. Julkapli, S. Bagheri, Int. J. Hydrogen Energy 2015, 40, 948979 
Q. Xiang, J. Yu, M. Jaroniec, Chem. Soc. Rev. 2012, 41, 782-796.

Y. Zhang, L. Zhang, C. Zhou, Acc. Chem. Res. 2013, 46, 23292339.

[27] A. Chakradhar, N. Sivapragasam, M. T. Nayakasinghe, U. Burghaus, Chem. Commun. 2015, 51, 11463-11466.

[28] Y.-J. Kim, J.-H. Lee, G.-C. Yi, Appl. Phys. Lett. 2009, 95, 213101.

[29] G. Imamura, K. Saiki, ACS Appl. Mater. Interfaces 2015, 7, 24392443.

[30] W. Luo, S. Zafeiratos, J. Phys. Chem. C 2016, 120, 14130-14139.

[31] W. Luo, S. Zafeiratos, ChemPhysChem 2016, 17, 3055-3061.

[32] Z. Peng, Z. Yan, Z. Sun, J. M. Tour, ACS Nano 2011, 5, 8241-8247.

[33] C. Y. Chen, D. Dai, G. X. Chen, J. H. Yu, K. Nishimura, C. T. Lin, N. Jiang, Z. L. Zhan, Appl. Surf. Sci. 2015, 346, 41-45.

[34] D. Q. McNerny, B. Viswanath, D. Copic, F. R. Laye, C. Prohoda, A. C. Brieland-Shoultz, E. S. Polsen, N. T. Dee, V. S. Veerasamy, A. J. Hart, Sci. Rep. 2014, 4, 5049.

[35] Z. Yan, Z. Peng, Z. Sun, J. Yao, Y. Zhu, Z. Liu, P. M. Ajayan, J. M. Tour, ACS Nano 2011, 5, 8187-8192.

[36] W. Xiong, Y. S. Zhou, L. J. Jiang, A. Sarkar, M. Mahjouri-Samani, Z. Q. Xie, Y. Gao, N. J. lanno, L. Jiang, Y. F. Lu, Adv. Mater. 2013, 25, 630-634.

[37] T. Ikuta, K. Gumi, Y. Ohno, K. Maehashi, K. Inoue, K. Matsumoto, Mater. Res. Express 2014, 1, 25028.

[38] J. Zhao, G. Zhu, W. Huang, Z. He, X. Feng, Y. Ma, X. Dong, Q. Fan, L. Wang, Z. Hu, et al., J. Mater. Chem. 2012, 22, 19679.

[39] S. Gaddam, C. Bjelkevig, S. Ge, K. Fukutani, P. A. Dowben, J. A. Kelber, J. Phys. Condens. Matter 2011, 23, 72204.

[40] A. Scott, A. Dianat, F. Börrnert, A. Bachmatiuk, S. Zhang, J. H. Warner, E. Borowiak-Paleń, M. Knupfer, B. Büchner, G. Cuniberti, et al., Appl. Phys. Lett. 2011, 98, 73110.

[41] M. H. Rümmeli, A. Bachmatiuk, A. Scott, F. Börrnert, J. H. Warner, V. Hoffman, J.-H. Lin, G. Cuniberti, B. Büchner, ACS Nano 2010, 4 4206-4210.

[42] H. Medina, Y. C. Lin, C. Jin, C. C. Lu, C. H. Yeh, K. P. Huang, K. Suenaga, J. Robertson, P. W. Chiu, Adv. Funct. Mater. 2012, 22, 2123-2128.

[43] K.-B. Kim, C.-M. Lee, J. Choi, J. Phys. Chem. C 2011, 115, 1448814493.

[44] Y. Miyasaka, A. Nakamura, J. Temmyo, Jpn. J. Appl. Phys. 2011, 50, 04DH12.

[45] P. R. Kidambi, B. C. Bayer, R. S. Weatherup, R. Ochs, C. Ducati, D. V. Szabó, S. Hofmann, Phys. Status Solidi - Rapid Res. Lett. 2011, 5, 341-343.

[46] W. Zhou, J. Zhu, C. Cheng, J. Liu, H. Yang, C. Cong, C. Guan, X. Jia, H. J. Fan, Q. Yan, et al., Energy Environ. Sci. 2011, 4, 49544961.

[47] S. Yang, X. Feng, S. Ivanovici, K. Müllen, Angew. Chemie - Int. Ed. 2010, 49, 8408-8411.

[48] J. Zhang, Z. Zhu, Y. Tang, X. Feng, J. Mater. Chem. A 2013, 1, 3752-3756.

[49] D. Wang, K. Zhang, Y. Zhu, Y. Lan, L. Hu, N. Lin, J. Zhou, Y. Qian, Mater. Lett. 2016, 175, 32-35.

[50] D. Wei, J. Liang, Y. Zhu, Z. Yuan, N. Li, Y. Qian, Part. Part. Syst. Charact. 2013, 30, 143-147.
[51] D. Wei, J. Liang, Y. Zhu, J. Zhang, X. Li, K. Zhang, Z. Yuan, Y. Qian, Electrochim. Acta 2013, 114, 779-784.

[52] B. L. Currin, R. M. Kennedy, A. N. Clarke, D. J. Wilson, Sep. Sci. Technol. 1979, 14, 669-687.

[53] D. I. Son, B. W. Kwon, D. H. Park, W.-S. Seo, Y. Yi, B. Angadi, C.-L. Lee, W. K. Choi, Nat. Nanotechnol. 2012, 7, 465-471.

[54] M.-Q. Yang, Y.-J. Xu, Phys. Chem. Chem. Phys. 2013, 15, 1910219118.

[55] R. G. Mendes, A. Bachmatiuk, A. A. El-Gendy, S. Melkhanova, R. Klingeler, B. Büchner, M. H. Rümmeli, J. Phys. Chem. C 2012, 116, 23749-23756.

[56] H. Liu, X. Dong, X. Wang, C. Sun, J. Li, Z. Zhu, Chem. Eng. J. 2013, 230, 79-85.

[57] N. Zhang, M. Yang, Z. Tang, Y. Xu, ACS Nano 2014, 8, 623-633.

[58] X. Li, N. Zhang, Y. J. Xu, ChemCatChem 2015, 7, 2047-2054.

[59] D. Chen, D. Wang, Q. Ge, G. Ping, M. Fan, L. Qin, L. Bai, C. Lv, K. Shu, Thin Solid Films 2015, 574, 1-9.

[60] Y. Zhang, Z. Tang, X. Fu, Y. Xu, ACS Nano 2010, 4, 7303-7314.

[61] M.-Q. Yang, C. Han, N. Zhanga, Y.-J. Xu, N. Zhang, Y.-J. Xu, Nanoscale 2015, 7, 18062-18070.

[62] M. Yang, Y. Xu, J. Phys. Chem. C 2013, 117, 21724-21734.

[63] Y. Zhang, N. Zhang, Z. Tang, Y. Xu, ACS Nano 2012, 6, 9777-9789.

[64] K. Lu, N. Zhang, C. Han, F. Li, Z. Chen, Y. Xu, J. Phys. Chem. C 2016, 120, acs.jpcc.6b06829.

[65] M.-Q. Yang, N. Zhang, M. Pagliaro, Y.-J. Xu, Chem. Soc. Rev. 2014, 43, 8240-8254.

[66] N. Zhang, M. Yang, S. Liu, Y. Sun, Y. Xu, Chem. Rev. 2015, 115, 10307-10377.

[67] C. Han, N. Zhang, Y. J. Xu, Nano Today 2016, 11, 351-372.

[68] N. Zhang, Y. Zhang, Y.-J. Xu, Nanoscale 2012, 4, 5792.

[69] N. Zhang, Y. Xu, CrystEngComm 2016, 18, 24-37.

[70] Y. Zhang, Z. Tang, X. Fu, Y. Xu, ACS Nano 2011, 9, 7426-7435.

[71] X. Pan, M.-Q. Yang, Y. Xu, Phys. Chem. Chem. Phys. 2014, 16, 5589-5599.

[72] W. Choi, A. Termin, M. R. Hoffmann, J. Phys. Chem. 1994, 98, 13669-13679.

[73] C. Wang, D. W. Bahnemann, J. K. Dohrmann, Chem. Commun. 2000, 95, 1539-1540.

[74] G. Yang, Z. Jiang, H. Shi, T. Xiao, Z. Yan, J. Mater. Chem. 2010, 20, 5301-5309.

[75] T. Ohno, T. Tsubota, K. Nishijima, Z. Miyamoto, Chem. Lett. 2004, 33, 750-751.

[76] H. Zhang, X. Lv, Y. Li, Y. Wang, J. Li, ACS Nano 2009, 4, 380-386.

[77] D. Wang, D. Choi, J. Li, Z. Yang, Z. Nie, R. Kou, D. Hu, C. Wang, L. V. Saraf, J. Zhang, et al., ACS Nano 2009, 3, 907-914.

[78] C. Wang, D. Meng, J. Sun, J. Memon, Y. Huang, J. Geng, Adv. Mater. Interfaces 2014, 1, 1300150.

[79] H. Kim, G. Moon, D. Monllor-Satoca, Y. Park, W. Choi, J. Phys. Chem. C 2012, 116, 1535-1543.

[80] H. G. Lee, G. Sai-Anand, S. Komathi, A. I. Gopalan, S. W. Kang, K. P. Lee, J. Hazard. Mater. 2015, 283, 400-409.

[81] Y. Bu, Z. Chen, W. Li, B. Hou, ACS Appl. Mater. Interfaces 2013, 5, 12361-12368.

[82] J. Zhai, L. Sun, H. Yu, H. Li, X. Zhang, H. Yang, J. Xu, J. 
Nanoparticle Res. 2014, 16, 2433.

[83]

Liwu, C. Hanyun, Z Ruilong, Z. Yongfa, J. Phys. Chem. C 2009, 113, 2368-2374.

[84] O. Akhavan, E. Ghaderi, J. Phys. Chem. C 2009, 113, 20214 20220.

[85] Z. Wei, Y. Chen, J. Wang, D. Su, M. Tang, S. Mao, Y. Wang, ACS Catal. 2016, 6, 5816-5822.

[86] R. V. Jagadeesh, A.-E. Surkus, H. Junge, M.-M. Pohl, J. Radnik, J. Rabeah, H. Huan, V. Schunemann, A. Bruckner, M. Beller, Science 2013, 342, 1073-1076.

[87]

S. Lin, C. Shen, D. Lu, C. Wang, H.-J. Gao, Carbon N. Y. 2013, 53, 112-119.

[88] Y. Zhao, B. Sun, X. Huang, H. Liu, D. Su, K. Sun, G. Wang, J. Mater. Chem. A 2015, 3, 5402-5408.

[89] R. R. C. M. Silva, H. A. Oliveira, A. C. P. F. Guarino, B. B. Toledo, M. B. T. Moura, B. T. M. Oliveira, F. B. Passos, Int. J. Hydrogen Energy 2016, 41, 6763-6772.

[90]
Delannoy, H. Lauron-Pernot, C. Louis, Catal. Sci. Technol. 2016, 6, 6794-6805.

[91] H. Xiong, T. J. Schwartz, N. I. Andersen, J. A. Dumesic, A. K. Datye, Angew. Chemie - Int. Ed. 2015, 54, 7939-7943.

[92] K. Cheng, V. Subramanian, A. Carvalho, V. V. Ordomsky, Y. Wang, A. Y. Khodakov, J. Catal. 2016, 337, 260-271.

[93] H. N. Pham, A. E. Anderson, R. L. Johnson, T. J. Schwartz, B. J. O'Neill, P. Duan, K. Schmidt-Rohr, J. A. Dumesic, A. K. Datye, ACS Catal. 2015, 5, 4546-4555.

[94] A. C. Ferrari, J. C. Meyer, V. Scardaci, C. Casiraghi, M. Lazzeri, F. Mauri, S. Piscanec, D. Jiang, K. S. Novoselov, S. Roth, et al., Phys. Rev. Lett. 2006, 97, 187401.

[95] A. C. Ferrari, D. M. Basko, Nat. Nanotechnol. 2013, 8, 235-246.

[96] A. C. Ferrari, Solid State Commun. 2007, 143, 47-57.

[97] W. S. Leong, C. T. Nai, J. T. L. Thong, Nano Lett. 2014, 14, 38403847 .

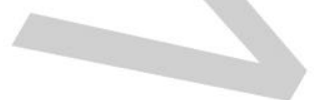


Entry for the Table of Contents (Please choose one layout)

Layout 1:

MINIREVIEW

Graphene coated oxides have been an emerging platform for both foundmental studies and applycations in catalysis. The latest advances in the synthesis and applications of graphene-coated oxides are reviewed. The chanllenges in the future studies are also discussed.

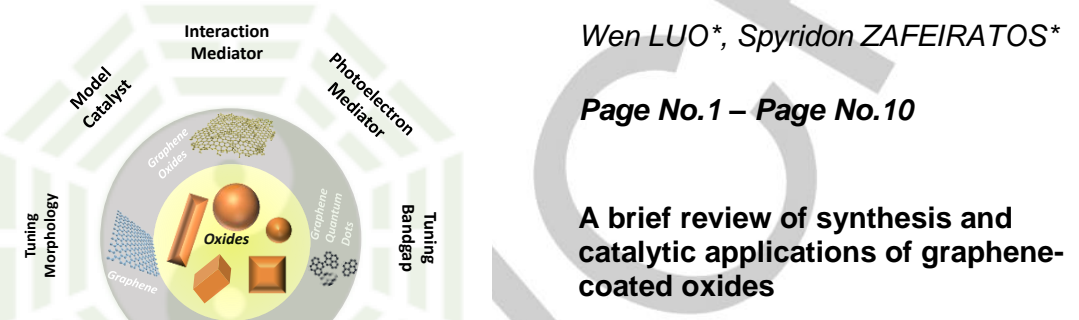
catalytic applications of graphenecoated oxides 